NASA/TM-2012-217646

II $-1>$

Effect of Solar Exposure on the Atomic Oxygen Erosion of Hubble Space Telescope AluminizedTeflon Thermal Shields

Aobo Guo and Claire C. Ashmead

Hathaway Brown School, Shaker Heights, Ohio

Kim K. de Groh

Glenn Research Center, Cleveland, Ohio

Edward A. Sechkar

ASRC Aerospace Corporation, Cleveland, Ohio 


\section{NASA STI Program . . . in Profile}

Since its founding, NASA has been dedicated to the advancement of aeronautics and space science. The NASA Scientific and Technical Information (STI) program plays a key part in helping NASA maintain this important role.

The NASA STI Program operates under the auspices of the Agency Chief Information Officer. It collects, organizes, provides for archiving, and disseminates NASA's STI. The NASA STI program provides access to the NASA Aeronautics and Space Database and its public interface, the NASA Technical Reports Server, thus providing one of the largest collections of aeronautical and space science STI in the world. Results are published in both non-NASA channels and by NASA in the NASA STI Report Series, which includes the following report types:

- TECHNICAL PUBLICATION. Reports of completed research or a major significant phase of research that present the results of NASA programs and include extensive data or theoretical analysis. Includes compilations of significant scientific and technical data and information deemed to be of continuing reference value. NASA counterpart of peer-reviewed formal professional papers but has less stringent limitations on manuscript length and extent of graphic presentations.

- TECHNICAL MEMORANDUM. Scientific and technical findings that are preliminary or of specialized interest, e.g., quick release reports, working papers, and bibliographies that contain minimal annotation. Does not contain extensive analysis.

- CONTRACTOR REPORT. Scientific and technical findings by NASA-sponsored contractors and grantees.
- CONFERENCE PUBLICATION. Collected papers from scientific and technical conferences, symposia, seminars, or other meetings sponsored or cosponsored by NASA.

- SPECIAL PUBLICATION. Scientific, technical, or historical information from NASA programs, projects, and missions, often concerned with subjects having substantial public interest.

- TECHNICAL TRANSLATION. Englishlanguage translations of foreign scientific and technical material pertinent to NASA's mission.

Specialized services also include creating custom thesauri, building customized databases, organizing and publishing research results.

For more information about the NASA STI program, see the following:

- Access the NASA STI program home page at http://www.sti.nasa.gov

- E-mail your question to help@sti.nasa.gov

- Fax your question to the NASA STI Information Desk at 443-757-5803

- Phone the NASA STI Information Desk at 443-757-5802

- Write to: STI Information Desk NASA Center for AeroSpace Information 7115 Standard Drive Hanover, MD 21076-1320 
NASA/TM-2012-217646

I.te

$\times+1 .+1$

Effect of Solar Exposure on the Atomic Oxygen Erosion of Hubble Space Telescope AluminizedTeflon Thermal Shields

Aobo Guo and Claire C. Ashmead

Hathaway Brown School, Shaker Heights, Ohio

Kim K. de Groh

Glenn Research Center, Cleveland, Ohio

Edward A. Sechkar

ASRC Aerospace Corporation, Cleveland, Ohio

Prepared for the

10th International Space Conference on Protection of Materials and Structures From the Space

Environment (ICPMSE-10J)

cosponsored by ITL, MDA, CSA, JAXA, Kobe University Graduate School of Engineering, and the Society for Promotion of Space Science

Bankoku-Shinryokan, Okinawa, Japan, June 12-17, 2011

National Aeronautics and

Space Administration

Glenn Research Center

Cleveland, Ohio 44135 


\section{Acknowledgments}

The authors would like to thank Marc Van Eesbeek of ESA for supplying the HST BSTS Weld section. Also, they appreciate the technical advice provided by Bruce Banks of Alphaport, Inc. at NASA Glenn Research Center. Finally, the authors would like to thank Patty Hunt, Director of Research at Hathaway Brown School, for making it possible for the student co-authors to collaborate with NASA on this and other research projects.

Trade names and trademarks are used in this report for identification only. Their usage does not constitute an official endorsement, either expressed or implied, by the National Aeronautics and Space Administration.

Level of Review: This material has been technically reviewed by technical management.

Available from

NASA Center for Aerospace Information 7115 Standard Drive

Hanover, MD 21076-1320
National Technical Information Service 5301 Shawnee Road Alexandria, VA 22312 


\title{
Effect of Solar Exposure on the Atomic Oxygen Erosion of Hubble Space Telescope Aluminized-Teflon Thermal Shields
}

\author{
Aobo Guo and Claire C. Ashmead \\ Hathaway Brown School \\ Shaker Heights, Ohio 44122 \\ Kim K. de Groh \\ National Aeronautics and Space Administration \\ Glenn Research Center \\ Cleveland, Ohio 44135 \\ Edward A. Sechkar \\ ASRC Aerospace Corporation \\ Cleveland, Ohio 44135
}

\begin{abstract}
When exposed to low Earth orbital (LEO) environment, external spacecraft materials degrade due to radiation, thermal cycling, micrometeoroid and debris impacts, and atomic oxygen (AO) interaction. Collisions between AO and spacecraft can result in oxidation of external spacecraft surface materials, which can lead to erosion and severe structural and/or optical property deterioration. It is therefore essential to understand the $\mathrm{AO}$ erosion yield $(E y)$, the volume loss per incident oxygen atom $\left(\mathrm{cm}^{3} /\right.$ atom), of polymers to assure durability of spacecraft materials. The objective of this study was to determine whether solar radiation exposure can increase the rate of $\mathrm{AO}$ erosion of polymers in LEO. The material studied was a section of aluminized-Teflon (DuPont) fluorinated ethylene propylene (Al-FEP) thermal shield exposed to space on the Hubble Space Telescope (HST) for 8.25 years. Retrieved samples were sectioned from the circular thermal shield and exposed to ground laboratory thermal energy AO. The results indicate that the average $E y$ of the solar facing HST Al-FEP was $1.9 \times 10^{-24} \mathrm{~cm}^{3} /$ atom, while the average $E y$ of the anti-solar HST Al-FEP was $1.5 \times 10^{-24} \mathrm{~cm}^{3} /$ atom. The $E y$ of the pristine samples was $1.6-1.7 \times 10^{-24} \mathrm{~cm}^{3} /$ atom. These results indicate that solar exposure affects the post-flight erosion rate of FEP in a plasma asher. Therefore, it likely affects the erosion rate while in LEO.
\end{abstract}

\section{Introduction}

When exposed to low Earth orbit (LEO), external spacecraft materials can degrade as a result of radiation, thermal cycling, micrometeoroid and debris impacts, and atomic oxygen (AO) interaction. AO is the most predominant chemical species in LEO, formed when ultraviolet (UV) radiation at wavelengths below $0.243 \mu \mathrm{m}$ causes diatomic oxygen to photodissociate (Ref. 1). The average impact energy of AO at International Space Station (ISS) altitudes $(\approx 400 \mathrm{~km}$ above the Earth) and at spacecraft orbital speeds of $\approx 7.7 \mathrm{~km} / \mathrm{s}$ is approximately $4.5 \mathrm{eV}$ (Ref. 2). Collisions of spacecraft with the residual AO can result in oxidation of the external spacecraft surfaces. Oxidation of susceptible materials, such as polymers, can result in fragmentation of the polymer chains and formation of volatile material causing erosion and resulting in severe structural and/or optical property deterioration. Atomic oxygen erosion of polymeric components, such as thermal control films and solar array blankets, can be a serious threat to spacecraft performance and durability. It is, therefore, essential to understand the $\mathrm{AO}$ erosion yield $(E y)$, the volume loss per incident oxygen atom $\left(\mathrm{cm}^{3} /\right.$ atom), of polymers to have knowledge of materials durability relevant to spacecraft applications (Ref. 2). Aside from AO, UV radiation can also cause significant alteration to polymeric surfaces, posing additional problems for spacecraft. Absorption of a photon of UV radiation by 
an organic molecule raises the molecule to an excited state, potentially stimulating bond dissociation and formation of free radicals that can cause further scission and crosslinking (Ref. 3). Because the solar facing sides of the thermal shields is hotter than the anti-solar sides, there can be increased mobility of the free radicals allowing them to react more readily thus causing more polymer chain damage that probably manifests itself as a reduction in elongation to failure. If sufficient ultraviolet radiation fluence is accumulated the degradation could end up causing the chopped polymer segments to be small enough to evaporate thus impacting optical and emittance. It can also cause degradation of mechanical properties, discoloration, and altered electrical properties (Ref. 4). Other forms of solar exposure, such as charged particle radiation, $\mathrm{x}$-rays from solar flares, and heating and thermal cycling, are additional environmental threats that can degrade spacecraft materials. The issue of whether solar radiation can increase the rate of $\mathrm{AO}$ erosion, hence the $\mathrm{AO}$ erosion yield, is of debate in the space community.

This research addresses the AO erosion of a commonly used spacecraft thermal control material, aluminized-Teflon fluorinated ethylene propylene (Al-FEP), specifically whether solar radiation exposure increases the rate of AO erosion. This study is unique in that it utilizes Al-FEP that has been exposed to the space environment for 8.25 years on the Hubble Space Telescope, material that was then retrieved by astronauts during a servicing mission and brought back to Earth.

Shortly after the Hubble Space Telescope (HST) was deployed into LEO on April 25, 1990, the metal bi-stem booms supporting the solar arrays (SA-I) were discovered to be rapidly contracting and expanding as the telescope orbited in and out of the Earth's shadow, causing a thermal-induced jitter (Ref. 5). In response to this problem, the European Space Agency (ESA) built new HST solar arrays (SA-II) with bi-stem thermal shields (BSTS) comprised of 2 mil $(0.051 \mathrm{~mm})$ Al-FEP rings fused together into circular bellows shape (with the FEP layer facing space) for thermal insulation (Ref. 5). Astronauts replaced the original arrays with the BSTS containing arrays during servicing mission 1 (SM1) in December 1991. Figure 1 shows the HST with SA-II and a close-up image of a section of BSTS. During the fourth servicing mission (SM3B) in March 2002 after experiencing 8.25 years of space exposure the SA-II were replaced with a third set of arrays (SA-III) and the SA-II was brought back to Earth. ESA provided a section of retrieved BSTS to NASA Glenn Research Center so that environmental durability studies of the Al-FEP could be conducted.

Because the thermal shields were wrapped around the solar array bi-stems and hence had solar, antisolar, and solar-grazing surfaces, the objective of this experiment was to characterize the AO Ey of retrieved HST BSTS Al-FEP with respect to solar angle to see if the Ey varied with solar exposure. The solar-facing surfaces were found to be extremely embrittled with through-thickness cracks, while the antisolar-facing side was very ductile, like pristine material (Ref. 5). It was therefore theorized that solarfacing Al-FEP would have a greater erosion yield, due to additional damage to the material induced from the solar radiation and/or heating caused by solar exposure. For this study 24 samples were sectioned from a single weld of the retrieved HST BSTS Al-FEP, and Ey values versus solar angle were determined using a RF plasma asher.
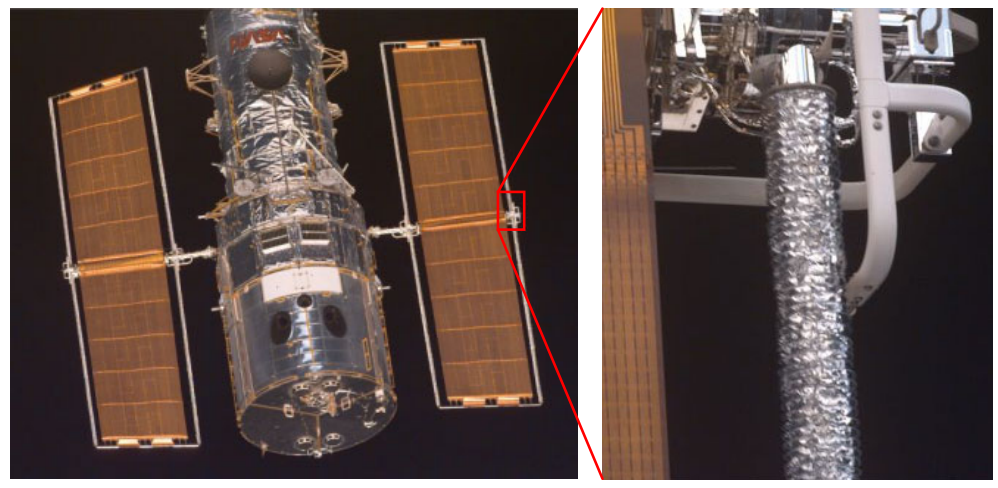

Figure 1.-Hubble Space Telescope with SA-II photographed in March 2002 during SM3B with a close-up photograph of a section of BSTS (Ref. 5). 


\section{Materials and Experimental Procedures}

\section{Materials}

The BSTS consisted of welded-together FEP rings whose backsides were coated with approximately 1000 - $\AA$ thick vapor-deposited aluminum and whose inner and outer diameters (when laid flat) were 6 and $10 \mathrm{~cm}$, respectively. Using an X-acto knife, the ESA-supplied 20 weld section was separated into 20 welds (Welds 1-20) by cutting through the inner fused region. Each weld consisted of two pieces of Al-FEP seamed at the top; these were then separated and consistently labeled either side A or side B. Both sides of Weld 15 were used for conducting this study (Side B in Test 1 and Side A in Test 2, as indicated in the Experimental Procedures section below).

For the purposes of this experiment, the direct solar-facing surface is defined as being $0^{\circ}$ and the antisolar-facing surface as $180^{\circ}$, with solar-grazing surfaces as $90^{\circ}$ and $270^{\circ}$. Researchers who examined the retrieved solar array and sectioned the BSTS 20-weld section stated that the most damaged (cracked) region of the BSTS was solar-facing on-orbit (Ref. 6). However, the exact position and thus the specific angle of the BSTS sample that was directly solar-facing was not known. Therefore, the $0^{\circ}$ position was chosen to be the center of the most obviously damaged region. Pristine Al-FEP samples (2 mil thick) obtained from Sheldahl and pristine BSTS samples fabricated at the same time as the HST BSTS for preflight environmental durability testing (Ref. 7) were also tested to provide control Ey values. Kapton $\mathrm{H}$ was used as an exposure reference because of its well-characterized in-space erosion yield $\left(3.0 \times 10^{-24} \mathrm{~cm}^{3} /\right.$ atom) (Ref. 8).

\section{Space Environmental Exposure}

The estimated environmental exposure conditions for the SA-II BSTS Al-FEP, installed during SM1 and retrieved during SM3B, are given in Table 1 (Ref. 5). Details on the computation of number of thermal cycles, equivalent sun hours (ESH), albedo solar exposure, x-ray fluence, electron and proton fluence, AO ram fluence, and thermal modeling are described by de Groh et al. in Reference 5. The ESH, X-ray fluence and $\mathrm{AO}$ fluence were adjusted for weld geometry with surfaces $23.5^{\circ}$ from sun incidence (Ref. 5).

AO ram fluences were modeled based on the Mass Spectrometer Incoherent Scatter Model 86 (MSIS-86) (Ref. 9). The AO fluences for solar-facing and anti-solar facing surfaces were determined by multiplying the ram fluence by 0.2528 and 0.3167 , respectively, (Ref. 10) and then were further adjusted by a factor of $0.399\left(\operatorname{cosine} 66.5^{\circ}\right)$ from the ram fluence value due to the weld geometry (Ref. 5).

TABLE 1.-ENVIRONMENTAL EXPOSURE CONDITIONS FOR HST BSTS SURFACES

\begin{tabular}{|c|c|c|}
\hline \multicolumn{2}{|c|}{ Exposure } & SM1 to SM3B (SA-II) \\
\hline \multicolumn{2}{|l|}{ Shuttle Missions } & STS-61 and STS-109 \\
\hline \multicolumn{2}{|l|}{ Mission dates } & December 1993 and March 2002 \\
\hline \multicolumn{2}{|l|}{ Exposure duration (Yrs) } & 8.25 \\
\hline \multicolumn{2}{|l|}{ Thermal cycles (\#) } & 45,100 \\
\hline \multicolumn{2}{|l|}{ Temperature range $\left({ }^{\circ} \mathrm{C}\right)$} & Anti-solar: -140 and Solar: +43 \\
\hline \multicolumn{2}{|c|}{ ESH, Solar-facing: Direct/Albedo/Total } & $\sim 19,600 / \sim 500 / \sim 20,000$ \\
\hline \multicolumn{2}{|c|}{ ESH, Anti-solar (albedo only) } & $\sim 6,200$ \\
\hline \multicolumn{2}{|c|}{ X-ray fluence: $1-8 \AA / 0.5-4 \AA\left(\mathrm{J} / \mathrm{m}^{2}\right)$} & $63.8 / 4.0$ \\
\hline \multicolumn{2}{|c|}{ Electron fluence $\left(\# / \mathrm{cm}^{2}\right),>40 \mathrm{keV}$} & $2.08 \times 10^{13}$ \\
\hline \multicolumn{2}{|c|}{ Proton fluence $\left(\# / \mathrm{cm}^{2}\right),>40 \mathrm{keV}$} & $2.55 \times 10^{10}$ \\
\hline \multirow{3}{*}{ AO fluence (atoms $/ \mathrm{cm}^{2}$ ) } & Ram & $1.2 \times 10^{21}$ \\
\hline & Solar & $1.2 \times 10^{20}$ \\
\hline & Anti-solar & $1.5 \times 10^{20}$ \\
\hline
\end{tabular}




\section{Experimental Procedures}

\section{Samples}

For Test 1, sixteen samples were sectioned from HST BSTS Weld 15 Side B at approximately every 20 to $30^{\circ}$. Eight samples (mostly solar grazing and anti-solar) were sectioned using a $1.1 \mathrm{~cm}$ diameter circular punch. Eight solar-facing samples were cut by hand using an X-acto knife to avoid cracks. Figure 2(a) shows the location where each of the samples was sectioned from Weld 15 Side B. Samples were then exposed to thermal energy AO in a Structure Probe, Inc. Plasma Prep II asher for Ey determination versus on-orbit solar angle. Multiple exposure tests were conducted to evaluate effects of $E y$ versus AO fluence. Seven of the irregularly shaped hand-cut samples were fragile and so were placed in small aluminum holders with circular apertures to provide support during handling and exposure, as well as to provide smaller exposure windows to AO than the sample holder (described below) provides, shown in Figure 2(b). The individual aluminum holders created to mount the irregularly shaped samples were exposed to AO prior to use to remove any organic coating that could contaminate the samples and contribute to erroneous results pertaining to mass loss.

For Test 2, eight samples were sectioned from the solar side of Weld 15 Side A. Five of the samples were obtained using a $1.1 \mathrm{~cm}$ diameter circular punch and three of the samples were cut by hand using an $\mathrm{X}$-acto knife. Once again, the three irregularly shaped samples were placed in pre-AO exposed individual aluminum holders. Samples in the individual Al holders in both tests were left in the holders during the entire test duration and were weighed while in the holders. Three $1.1 \mathrm{~cm}$-diameter pristine BSTS samples, three $1.1 \mathrm{~cm}$ diameter pristine Al-FEP samples, and two $2.54 \mathrm{~cm}$ diameter Kapton $\mathrm{H}$ samples were also sectioned using circular punches. Samples obtained between $270^{\circ}$ clockwise to $90^{\circ}$ are considered "solarfacing" samples while those obtained between $90^{\circ}$ clockwise to $270^{\circ}$ are termed "anti-solar," corresponding with the Sample Angle Template shown in Figure 2(a). Samples at $90^{\circ}$ and $270^{\circ}$ are referred to as "solar-grazing". It should be noted that the angles of samples sectioned from Side A match those of the Side B samples, since samples at a particular angle (such as $60^{\circ}$ ) were facing the same direction on the telescope.

\section{Mass Measurements}

The erosion yield values obtained for this experiment were determined based on mass loss. Due to the hygroscopic nature of Kapton $\mathrm{H}$ polyimide, all Kapton $\mathrm{H}$ samples were either dehydrated for at least $48 \mathrm{hr}$ prior to measuring their masses (as in the case of the Kapton flux test) or prioritized to be immediately weighed once taken out of the asher (as in the case of the Kapton witness sample in each test exposure).

A test was conducted to compare the dehydrated weight of Al-FEP to non-dehydrated weight. Al-FEP sample weights were found to not vary significantly when dehydrated, therefore the Al-FEP samples were not dehydrated prior to sample weighing. All sample weights were obtained using a Mettler Balance with a sensitivity of $\pm 1 \mu \mathrm{g}$.

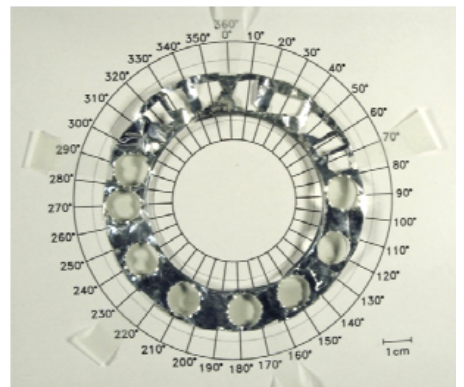

(a)

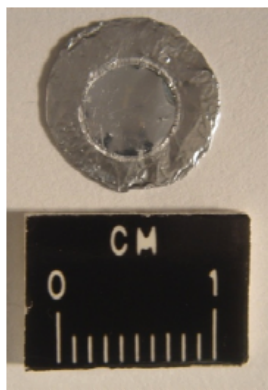

(b)

Figure 2.-(a) Weld 15 Side B after sectioning of 16 test samples at specified angles, and (b) an irregularly shaped sample from Weld 15 Side A in its Al holder. 


\section{Ground-Laboratory RF Plasma Asher Exposure}

The samples were exposed to AO in a Structured Probe, Inc. Plasma Prep II asher, which generates a plasma by exciting the ambient air with $100 \mathrm{~W}$ of continues RF power at $13.56 \mathrm{MHz}$. The operation pressure was between $0.5-1.0 \times 10^{2}$ mtorr. The samples were exposed to AO while being held in a metal sample holder with a large central opening for a Kapton fluence witness sample $(2.54 \mathrm{~cm}$ diameter $)$ and with 22 smaller sample openings ( $1.1 \mathrm{in} . \mathrm{cm}$ diameter). Figure 3 shows the sample holder loaded with Kapton samples for a flux test (described below) along with sample position descriptions noted (A-Y).

Each test included six individual AO exposures, so that the effect of fluence on $E y$ could be determined. The same sample was always placed in the same position for each incremental exposure. Aside from protecting the edges and backs of the samples from the AO plasma and keeping the samples from curling during exposure, the holder also provided a well-defined exposure area necessary for further calculations. The holder was always placed in the same position in the asher in an effort to ensure the same flux $\left(f\right.$, atoms $\left./\left(\mathrm{cm}^{2} \mathrm{~s}\right)\right)$ for each sample position.

The $2.54 \mathrm{~cm}$ diameter Kapton $\mathrm{H}$ fluence witness sample was placed in position $\mathrm{Y}$ in the metal holder for every test in order to determine the AO effective fluence $\left(F\right.$, atoms $\left./ \mathrm{cm}^{2}\right)$. The fluence of each sample in every exposure needed to be calculated to compute erosion yield, and finding individual sample fluences is discussed in the Flux Tests section below. As stated previously, Kapton $\mathrm{H}$ is used as a fluence reference because of its well-characterized in-space erosion yield in LEO. The equation to compute the exposure fluence in the asher is provided in Equation (1).

$$
F=\frac{\Delta M_{K}}{A_{K \rho K} E_{K}}
$$

where

$$
\begin{array}{ll}
F & \text { plasma asher effective AO fluence }\left(\text { atoms } / \mathrm{cm}^{2}\right) \\
\Delta M_{K} & \text { mass loss of Kapton H witness sample }(\mathrm{g}) \\
A_{K} & \text { exposed surface area of Kapton } \mathrm{H} \text { witness sample }\left(\mathrm{cm}^{2}\right) \\
\rho_{K} & \text { density of Kapton } \mathrm{H}\left(1.4273 \mathrm{~g} / \mathrm{cm}^{3}\right)(\text { Ref. } 5) \\
E_{K} & \text { erosion yield of Kapton } \mathrm{H}\left(3.00 \times 10^{-24} \mathrm{~cm}^{3} / \text { atom) }(\text { Ref. } 8)\right.
\end{array}
$$

As mentioned, two tests were conducted, each with samples from a different Weld Side: Test 1 included Side B samples and Test 2 included Side A samples. For each test, the samples were exposed to six different individual $\mathrm{AO}$ exposures and their $E y$ were determined. Exposures 1 and 2 were $3.5 \mathrm{hr}$ each, exposure 3 was $7 \mathrm{hr}$, exposure 4 was $14 \mathrm{hr}$, and exposures 5 and 6 were $28 \mathrm{hr}$ each, for a total exposure of $84 \mathrm{hr}$ per test. The fluence values of Test 1 ranged from $\approx 1.5 \times 10^{19}$ atoms $/ \mathrm{cm}^{2}$ for Exposure 1 to a cumulative fluence of $\approx 1.3 \times 10^{21}$ atoms $/ \mathrm{cm}^{2}$ (depending on position). The fluence values of Test 2 ranged from $\approx 1.9 \times 10^{19}$ atoms $/ \mathrm{cm}^{2}$ for Exposure 1 to a cumulative fluence of $\approx 1.4 \times 10^{21}$ atoms $/ \mathrm{cm}^{2}$.

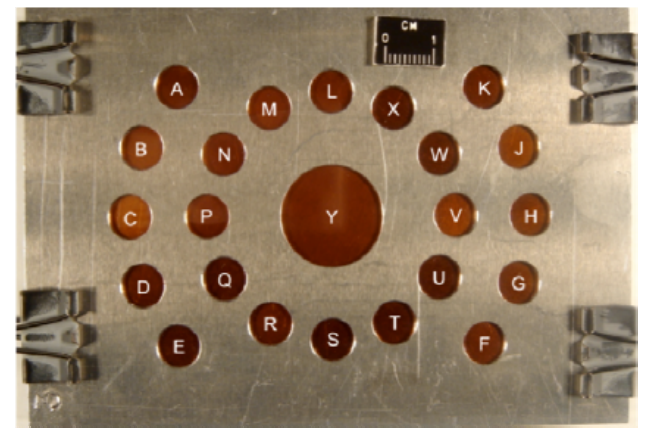

Figure 3.-Sample holder with 23 Kapton $\mathrm{H}$ samples and position identifications. 


\section{Flux Tests}

The AO fluence of the individual test samples was calculated because flux can vary with position in the asher. A Kapton $\mathrm{H}$ flux test was conducted to determine the effective flux of each of the 23 positions, with a Kapton $\mathrm{H}$ witness sample in each position of the sample holder. Since the fluence of a Kapton $\mathrm{H}$ sample can be determined using Equation (1), and because flux is simply fluence divided by time in seconds, the effective flux for each position was determined based on mass loss of each individual Kapton H sample. Twenty-two $k$ constants, one corresponding to each of the 22 positions in the holder, were then calculated, compensating for the position-based flux variation relative to the central $2.54 \mathrm{~cm}$ diameter Kapton $\mathrm{H}$ witness sample $(k=1)$. The $k$ constants were then used to calculate the precise flux and fluence each sample was exposed to in every test. The $k$ constants were based on the positional flux relative to the Kapton $\mathrm{H}$ sample flux in position $\mathrm{Y}$, as shown in Equation (2):

$$
f_{n}=k_{n} \times f_{k}
$$

where
$f_{n} \quad$ flux of the sample in position $\mathrm{n}$ (atoms $/ \mathrm{cm}^{2} \mathrm{sec}$ )
$n \quad$ sample holder position
$k_{n} \quad$ constant, a fraction of the fluence of a sample in position $\mathrm{n}$ relative to the fluence of the Kapton $\mathrm{H}$ in position $\mathrm{Y}\left(k_{n}=1\right.$ for Kapton $\left.\mathrm{H}\right)$
$f_{k} \quad$ flux of Kapton $\mathrm{H}$ witness sample

Two separate flux tests were conducted and the resulting $k$ values for each sample position were averaged. In order to calculate the fluence each sample was exposed to during each individual test, the effective fluence was determined for the Kapton $\mathrm{H}$ witness sample in position $\mathrm{Y}$ and then multiplied by the average $k$ factor for each position to obtain the fluence for each sample position.

\section{Exposure Area Measurements}

The exposure area of each sample opening in the metal holder was calculated by taking diameter measurements in three orientations using Fowler \& NSK Max-Cal electronic digital calipers and averaging the values. For the irregularly shaped samples, the exposed surface area was found by tracing the exposed perimeter of the samples (from photographs of the samples taken with a scale bar) using AutoCAD, a computer aided design software program. An example of this technique can be seen in Figure 4, where the perimeter of the surface area is outlined in red.

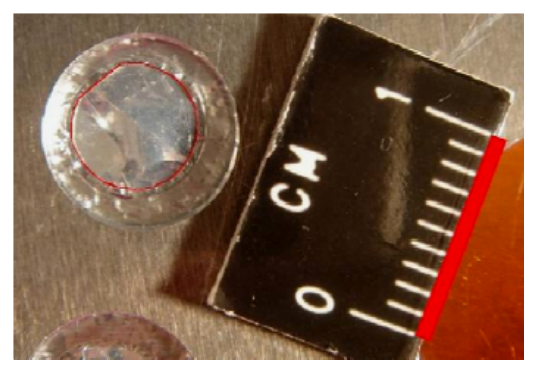

Figure 4.-Photograph of HST-BSTS $30^{\circ}$ sample (position $\mathrm{N}$ ) prior to the first exposure showing the AutoCAD trace line used for surface area calculation. 


\section{Erosion Yield Calculation}

Once mass loss, fluence, density, and exposure area values were obtained, the erosion yield $\left(E_{y}\right)$ was calculated using Equation (3):

$$
E_{y}=\frac{\Delta M_{S}}{\left(A_{S \rho S} F\right)}
$$

where
$\Delta M_{S} \quad$ mass loss of sample $(\mathrm{g})$
$A_{S} \quad$ exposed surface area of sample exposed to atomic oxygen $\left(\mathrm{cm}^{2}\right)$
$\rho_{S} \quad$ density of sample $\left(\mathrm{g} / \mathrm{cm}^{3}\right)$
$F \quad$ plasma asher Kapton $\mathrm{H}$ effective $\mathrm{AO}$ fluence $\left(\right.$ atoms $\left./ \mathrm{cm}^{2}\right)$

\section{Photo-Documentation}

Close-up photographs were taken of the irregularly shaped samples before and after each exposure using a Canon digital camera mounted on a Landcamera stand so that surface area measurements could be obtained using AutoCAD.

\section{Results and Discussion}

The solar-facing side of the BSTS was found to be extremely embrittled with numerous throughthickness cracks and pieces of insulation material missing in some places. Visually, the anti-solar side of Weld 15 did not appear to be degraded. These observations are consistent with mechanical property degradation studies conducted by de Groh et al. (Ref. 5) on other Welds from the 20-Weld section provided by ESA.

\section{Material Degradation}

Figures 5(a) and (b) provide photographs of solar facing HST BSTS sample $299^{\circ}$ (position M) from Test 2 wrapped in its Al holder in the sample holder prior to AO exposure and after the fifth AO exposure, respectively. This sample provides an example of a sample that was excessively degraded after the fifth exposure. The pre-exposure surface area was $0.153 \mathrm{~cm}^{2}$, while the surface area after Exposure 5 was $0.141 \mathrm{~cm}^{2}$. The blue ovals in the images highlight a distinguishing feature in the small $\mathrm{Al}$ holder, while the excess erosion can be seen in Figure 5(b) in the upper left section of the sample where a piece of material is missing.

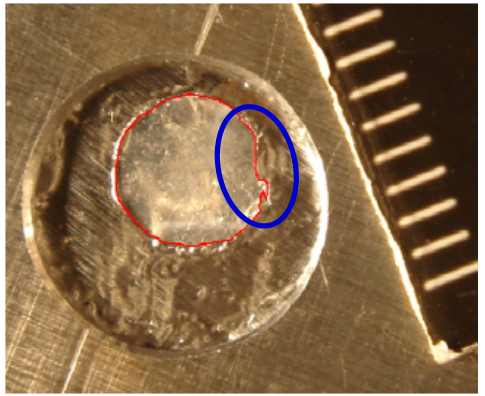

(a)

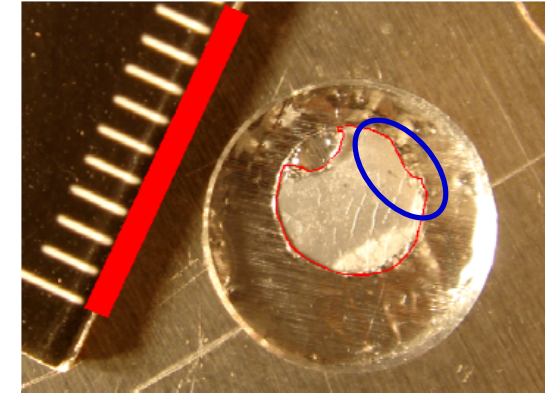

(b)

Figure 5.-HST BSTS sample $299^{\circ}$ (position M) from Test 2 in small Al holder in sample holder: a) prior to AO exposure, and b) after the fifth AO exposure. 
Although both the pristine samples (pristine Al-FEP and pristine BSTS) and the anti-solar-facing samples became hazy-white with AO exposure, none of these samples were found to be excessively degraded after the full AO exposure. Some of the solar-facing samples that were excessively eroded, such as HST BSTS sample $10^{\circ}$, appear to have warped and/or curled during exposure. This warping would lead to the post-exposure photographs misrepresenting their surface area, resulting in their true surface areas differing from the ones computed. As this would introduce error into the Ey values, it was concluded that the cumulative Ey values should not include these higher fluence exposures.

\section{Fluence and Erosion Yield Values}

Seven of the samples in Test 1 were found to be excessively degraded after the sixth exposure and three of the samples in Test 2 were found to be excessively degraded after the fifth exposure. Therefore the cumulative $E y$ for the Test 1 samples is based on data from Exposures 1-5, and the cumulative Ey for the Test 2 samples is based on data from Exposures 1-4. It should be noted that in a couple of the individual exposures, there were a few surprisingly low mass loss values. In these situations (BSTS sample $65^{\circ}$ in Test 1 , BSTS sample $299^{\circ}$ in Test 2, and Pristine Al-FEP (Position C in Test 1)) the fluences for those individual test exposures were not included when computing the cumulative Ey values. The Polar Plot shown in Figure 6 shows Ey versus solar angle for the HST BSTS samples, along with average $E y$ values for the pristine Al-FEP samples and pristine HST BSTS samples (represented as dashed and solid lines, respectively).

As can be seen in Figure 6, the asher Ey values of the anti-solar samples are slightly lower (average $E y$ of $1.48 \times 10^{-24} \mathrm{~cm}^{3}$ /atom) than the average $E y$ values for the pristine BSTS and pristine Al-FEP, which were found to be $1.66 \times 10^{-24} \mathrm{~cm}^{3} /$ atom and $1.63 \times 10^{-24} \mathrm{~cm}^{3} /$ atom, respectively. Although there is a fair amount of scatter in the $E y$ of the solar-facing samples, the majority of solar-facing $E y$ values are higher

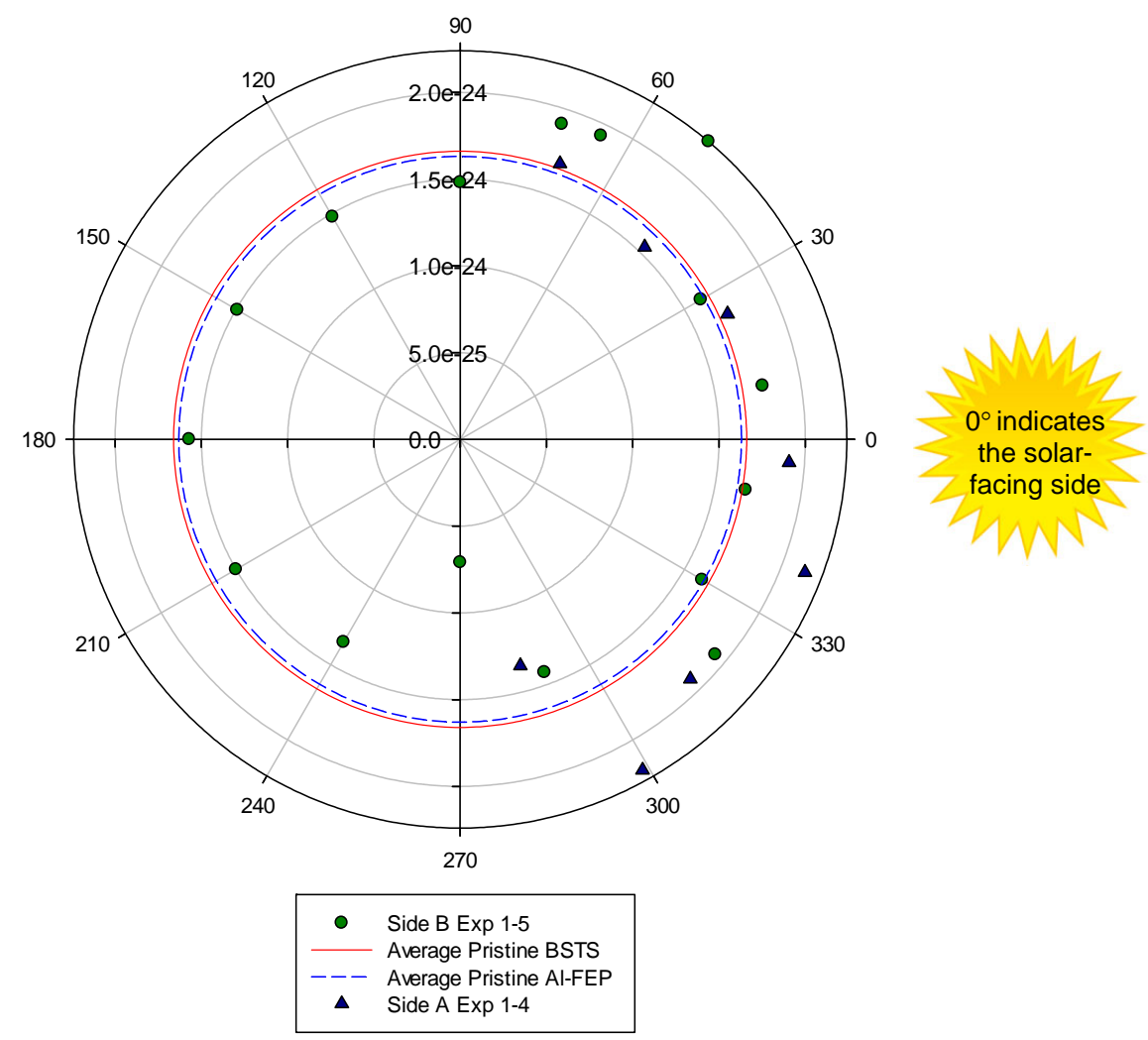

Figure 6.-Polar Plot of Ey versus solar angle for pristine and HST BSTS samples. 
than those for the anti-solar or pristine samples. The average $E y$ for side B of the solar facing HST BSTS sample was calculated as $1.79 \times 10^{-24} \mathrm{~cm}^{3} /$ atom, and side A was $1.94 \times 10^{-24} \mathrm{~cm}^{3} /$ atom. The average $E y$ for the solar facing HST BSTS sample was computed to be $1.86 \times 10^{-24} \mathrm{~cm}^{3} /$ atom, and the Anti-solar side was calculated as $1.48 \times 10^{-24} \mathrm{~cm}^{3} /$ atom (Test 1 exposures 1-5 and Test 2 exposures 1-4). There was a 26 percent difference between HST BSTS Average Solar and Average Anti-Solar Ey.

Another observation that can be made from Figure 6 is that the $E y$ of samples centered around the $270^{\circ}$ solar-grazing angle (samples $270^{\circ}, 290^{\circ}, 285^{\circ}$, and $240^{\circ}$ ) are lower than all the other Ey values. This is particularly true for the HST BSTS $270^{\circ}$ sample, which had an $E y$ of only $7.10 \times 10^{-25} \mathrm{~cm}^{3} /$ atom, only half the $E y$ of the HST BSTS solar-grazing sample $90^{\circ}$ of $1.48 \times 10^{-24} \mathrm{~cm}^{3} /$ atom. After examining the HST BSTS $270^{\circ}$ sample under the microscope, it was observed that this sample has a patchy appearance and contains some crazed areas, as shown in Figure 7. Therefore, it appears that this sample may contain a layer of contamination. The orientation of the sample was such that silicone contamination from the silicone on the anti-solar side of the array could be possible.

In a study by de Groh et al., pristine, solar-facing, anti-solar-facing and solar-grazing BSTS samples were examined with scanning electron microscopy for surface morphology and with energy dispersive spectroscopy (EDS) for surface chemistry. The pristine, solar-facing and anti-solar-facing surfaces did not have any evidence of contamination, with only $\mathrm{C}$ and $\mathrm{F}$ peaks observed (Ref. 5). However, a crazed surface texture was observed on one of the solar-grazing samples (Ref. 5). The EDS data indicate the crazed texture is due to silicone contamination (the Pd peak is from the conductive coating) (Ref. 5). The back surfaces of the solar arrays were coated with DC 93-500 silicone, so it appears that the solar-grazing surface facing the array received silicone contamination from the solar arrays, which impacted the asher $E y$ values in this test. If the anti-solar samples also received very small amounts of contamination on-orbit (perhaps below the detection limit of EDS), this would explain the slightly lower Ey values of the antisolar samples compared with those of the pristine samples.

It should be noted that the erosion yield of Teflon FEP in a plasma asher can be substantially higher that the erosion yield in LEO. For example, the erosion yield of FEP determined after 4 years of space exposure on the International Space Station as part of the Materials International Space Station Experiment 2 (MISSE-2) was found to be $2.00 \times 10^{-25} \mathrm{~cm}^{3} /$ atom, (Ref. 11) which is an order of magnitude lower than the $E y$ determined in this study using a plasma asher. It should also be noted that de Groh et al. have shown a correlation of increased erosion yield with increased ESH for Teflon FEP from numerous spaceflight experiments (Ref. 12).

In summary, the average $E y$ values of the solar-facing HST BSTS samples were found to be 26 percent higher than the $E y$ of the anti-solar-facing samples, and 12 to 15 percent higher than pristine BSTS or Al-FEP samples, respectively. These results indicate that solar exposure affects the post-flight erosion rate of FEP in a plasma asher. Therefore, it likely affects the erosion rate while in LEO. It is important that spacecraft engineers consider the enhanced erosion of Teflon FEP on solar-facing surfaces when designing durable spacecraft components.

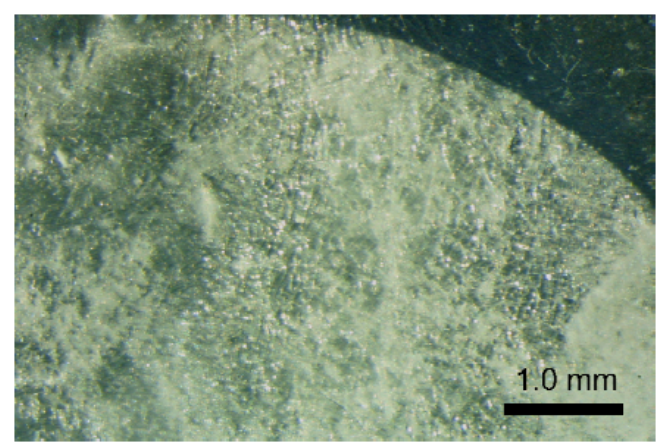

(a)

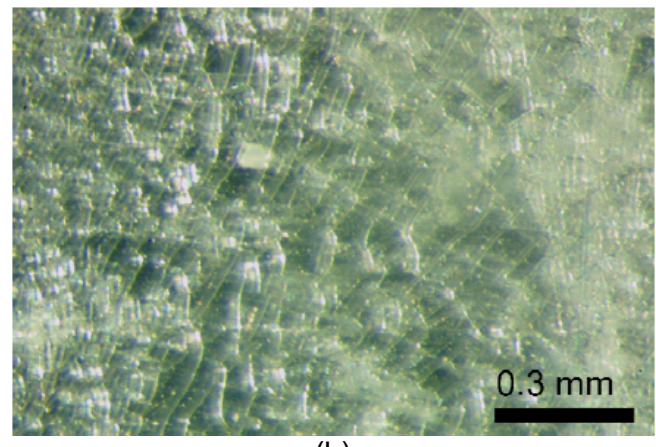

(b)

Figure 7.- Solar-grazing Sample 270 : (a) both the exposed and protected (upper right) areas of the sample can be seen, and (b) close-up showing the crazed surface. 


\section{Summary}

To determine whether solar exposure affects the rate of atomic oxygen erosion of Al-FEP, a very commonly used spacecraft thermal control material, ground-laboratory AO experiments have been performed on space exposed FEP. The material studied was a section of Al-FEP thermal shield exposed to space on the HST for 8.25 years. In these investigations, samples were sectioned from the circular thermal shield and exposed to AO in an air-operated radio-frequency plasma asher for $E y$ determination versus on-orbit solar angle. The $E y$ values of 24 HST BSTS samples were determined in a series of two separate tests, with the $E y$ values compared relative to Kapton $\mathrm{H}$ in an asher. Along with pristine BSTS and Al-FEP samples, the Ey values of the HST samples were determined for six different exposure tests. Cumulative $E y$ were calculated, though, because error had to be taken into account; the most accurate data excluded the last exposure for Test 1 and the last two exposures for Test 2. The average Ey of the solar facing HST Al-FEP was found to be $1.9 \times 10^{-24} \mathrm{~cm}^{3} /$ atom, while the average $E y$ of the anti-solar HST Al-FEP was $1.5 \times 10^{-24} \mathrm{~cm}^{3} /$ atom. The $E y$ of the pristine samples was $1.6-1.7 \times 10^{-24} \mathrm{~cm}^{3} /$ atom. These results indicate that radiation and solar exposure affects the post-flight erosion rate of FEP in a plasma asher. Therefore, it likely affects the erosion rate while in LEO.

In addition, it was determined that one of the solar-grazing surfaces $\left(270^{\circ}\right)$ was contaminated on-orbit with silicone contamination, likely the surface facing the solar arrays, which impacted the erosion yield of samples in that orientation. Last, the erosion yield versus fluence comparisons shows that the rate of erosion of all samples is greater at the surface of the sample, and that solar-facing samples in particular have higher rates of erosion than other samples for fluences below $\approx 5.0 \times 10^{20}$ atoms $/ \mathrm{cm}^{2}$. By using this fluence and the solar facing erosion yield determined in this study, it appears that solar radiation reacted with the FEP to a depth of $\approx 9 \mu \mathrm{m}$.

\section{References}

1. Dickerson, R.E., Gray, H.B., and Haight, G.P., Chemical Principles $3^{\text {rd }}$ Edition, Benjamin Cummings Publishing Co. Inc. Menlo Park, CA, 1979, p. 457.

2. Banks, B.A., Miller, S.K., and de Groh, K.K., AIAA-2004-5638; also NASA/TM-2004-213223, 2004.

3. Dever, J.A., NASA Technical Memorandum-103711. 1991.

4. J.A. Dever, B.A. Banks, K.K. de Groh and S.K. Miller, Degradation of Spacecraft Materials, in Handbook of Environmental Degradation of Materials, Myer Kutz (editor), William Andrew Publishing, pp. 465-501, 2005.

5. de Groh, K.K., Finlay, K.A., Snyder, A., High Performance Polymers 20 (2008) 410-428.

6. (pers. comm. M. Van Eesbeek, ESA, 2004)

7. Dever, J.A. and de Groh, K.K., NASA/TM-2002-211364, 2002.

8. Banks, B.A., "The Use of Fluoropolymers in Space Applications," Ch. 4 in Modern Fluoropolymers: High Performance Polymers for Diverse Applications, John Wiley \& Sons, Ltd., 1997.

9. Hedin A.E. 1987, MSIS-86 thermospheric model J. Geophys. Res. 92 4649-62.

10. Rockwell International Corporation. (1990). Rocketdyne Division, Seal Beach, CA, USA, Specification RC 1800 Review C, p.18, 1990.

11. de Groh, K.K., Banks, B.A., McCarthy, C.E., Rucker, R.N., Roberts L.M. and Berger, L.A., High Performance Polymers 20 (2008) 388-409.

12. de Groh, K.K., Banks, B.A., Guo, A., Ashmead, C.C., Mitchell G.G. and Yi., G.T., "MISSE 6 Polymers Atomic Oxygen Erosion Data," Presented at the 2010 NSMMS held June 28-July 1, 2010 in Scottsdale, AZ. 



\begin{tabular}{|c|c|c|}
\hline \multicolumn{2}{|c|}{ REPORT DOCUMENTATION PAGE } & $\begin{array}{l}\text { Form Approved } \\
\text { OMB No. 0704-0188 }\end{array}$ \\
\hline \multicolumn{3}{|c|}{ 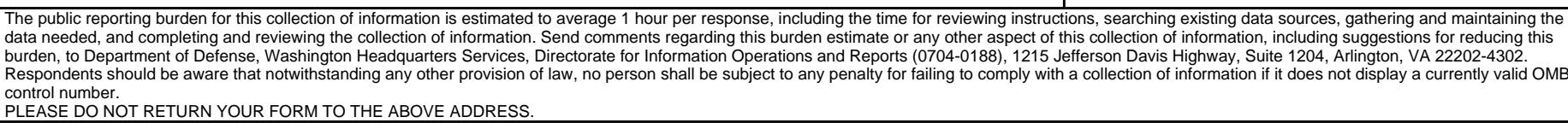 } \\
\hline $\begin{array}{l}\text { 1. REPORT DATE (DD-MM-YYYY) } \\
01-09-2012\end{array}$ & $\begin{array}{l}\text { 2. REPORT TYPE } \\
\text { Technical Memorandum }\end{array}$ & 3. DATES COVERED (From - To) \\
\hline \multirow{3}{*}{\multicolumn{2}{|c|}{$\begin{array}{l}\text { 4. TITLE AND SUBTITLE } \\
\text { Effect of Solar Exposure on the Atomic Oxygen Erosion of Hubble Space Telescope } \\
\text { Aluminized-Teflon Thermal Shields }\end{array}$}} & 5a. CONTRACT NUMBER \\
\hline & & 5b. GRANT NUMBER \\
\hline & & 5c. PROGRAM ELEMENT NUMBER \\
\hline \multirow{3}{*}{\multicolumn{2}{|c|}{$\begin{array}{l}\text { 6. AUTHOR(S) } \\
\text { Guo, Aobo; Ashmead, Claire, C.; de Groh, Kim, K.; Sechkar, Edward, A. }\end{array}$}} & 5d. PROJECT NUMBER \\
\hline & & 5e. TASK NUMBER \\
\hline & & $\begin{array}{l}\text { 5f. WORK UNIT NUMBER } \\
\text { WBS 315404.07.20.12 }\end{array}$ \\
\hline \multicolumn{2}{|c|}{$\begin{array}{l}\text { 7. PERFORMING ORGANIZATION NAME(S) AND ADDRESS(ES) } \\
\text { National Aeronautics and Space Administration } \\
\text { John H. Glenn Research Center at Lewis Field } \\
\text { Cleveland, Ohio 44135-3191 }\end{array}$} & $\begin{array}{l}\text { 8. PERFORMING ORGANIZATION } \\
\text { REPORT NUMBER } \\
\text { E-18323 }\end{array}$ \\
\hline \multirow{2}{*}{\multicolumn{2}{|c|}{$\begin{array}{l}\text { 9. SPONSORING/MONITORING AGENCY NAME(S) AND ADDRESS(ES) } \\
\text { National Aeronautics and Space Administration } \\
\text { Washington, DC 20546-0001 }\end{array}$}} & $\begin{array}{l}\text { 10. SPONSORING/MONITOR'S } \\
\text { ACRONYM(S) } \\
\text { NASA }\end{array}$ \\
\hline & & $\begin{array}{l}\text { 11. SPONSORING/MONITORING } \\
\text { REPORT NUMBER } \\
\text { NASA/TM-2012-217646 }\end{array}$ \\
\hline \multicolumn{3}{|c|}{$\begin{array}{l}\text { 12. DISTRIBUTIONIAVAILABILITY STATEMENT } \\
\text { Unclassified-Unlimited } \\
\text { Subject Categories: } 27 \text { and } 18 \\
\text { Available electronically at http://wWw.sti.nasa.gov } \\
\text { This publication is available from the NASA Center for AeroSpace Information, 443-757-5802 }\end{array}$} \\
\hline
\end{tabular}

\section{ABSTRACT}

When exposed to low Earth orbital (LEO) environment, external spacecraft materials degrade due to radiation, thermal cycling, micrometeoroid and debris impacts, and atomic oxygen (AO) interaction. Collisions between AO and spacecraft can result in oxidation of external spacecraft surface materials, which can lead to erosion and severe structural and/or optical property deterioration. It is therefore essential to understand the AO erosion yield (Ey), the volume loss per incident oxygen atom ( $\mathrm{cm}^{3} /$ atom), of polymers to assure durability of spacecraft materials. The objective of this study was to determine whether solar radiation exposure can increase the rate of AO erosion of polymers in LEO. The material studied was a section of aluminized-Teflon (DuPont) fluorinated ethylene propylene (Al-FEP) thermal shield exposed to space on the Hubble Space Telescope (HST) for 8.25 years. Retrieved samples were sectioned from the circular thermal shield and exposed to ground laboratory thermal energy AO. The results indicate that the average Ey of the solar facing HST Al-FEP was $1.9 \times 10^{-24} \mathrm{~cm}^{3} /$ atom, while the average Ey of the anti-solar HST Al-FEP was $1.5 \times 10^{-24} \mathrm{~cm}^{3} /$ atom. The Ey of the pristine samples was 1.6 $1.7 \times 10^{-24} \mathrm{~cm}^{3} /$ atom. These results indicate that solar exposure affects the post-flight erosion rate of FEP in a plasma asher. Therefore, it likely affects the erosion rate while in LEO.

\section{SUBJECT TERMS}

Hubble Space Telescope (HST); Thermal control insulation; Space environment; Environmental degradation; Polymer; Atomic oxygen (AO); Solar radiation

\begin{tabular}{|c|c|c|c|c|c|}
\hline \multicolumn{3}{|c|}{ 16. SECURITY CLASSIFICATION OF: } & \multirow{2}{*}{$\begin{array}{l}\text { 17. LIMITATION OF } \\
\text { ABSTRACT } \\
\text { UU }\end{array}$} & \multirow{2}{*}{$\begin{array}{l}\text { 18. NUMBER } \\
\text { OF } \\
\text { PAGES } \\
18\end{array}$} & \multirow{2}{*}{$\begin{array}{l}\text { 19a. NAME OF RESPONSIBLE PERSON } \\
\text { STI Help Desk (email:help@sti.nasa.gov) } \\
\text { 19b. TELEPHONE NUMBER (include area code) } \\
\text { 443-757-5802 }\end{array}$} \\
\hline $\begin{array}{l}\text { a. REPORT } \\
U\end{array}$ & $\begin{array}{l}\text { b. ABSTRACT } \\
U\end{array}$ & $\begin{array}{l}\text { c. THIS } \\
\text { PAGE } \\
\text { U }\end{array}$ & & & \\
\hline
\end{tabular}



